\title{
Chrysin inhibits human airway smooth muscle cells proliferation through the extracellular signal-regulated kinase 1/2 signaling pathway
}

\author{
JING YAO, YUN-SHI ZHANG, GAN-ZHU FENG ${ }^{*}$ and QIANG DU* \\ Department of Respiratory Medicine, The Second Affiliated Hospital of Nanjing Medical University, \\ Nanjing, Jiangsu 210011, P.R. China
}

Received December 7, 2014; Accepted September 1, 2015

DOI: $10.3892 / \mathrm{mmr} .2015 .4401$

\begin{abstract}
Asthma is a chronic airway inflammatory disease characterized by an increased mass of airway smooth muscle (ASM). Chrysin (5,7-dihydroxyflavone), a natural flavonoid, has been shown to exert multiple biological activities, including anti-inflammatory, anti-proliferative and anti-oxidant effects, as well as the potency to ameliorate asthma in animal models. The objective of the present study was to identify the underlying mechanism of the therapeutic effects of chrysin. The impact of chrysin on basal and platelet-derived growth factor (PDGF)-induced proliferation and apoptosis of human airway smooth muscle cells (HASMCs) was investigated. Furthermore, the activation of the extracellular signal-regulated protein kinase (ERK) signaling pathway was evaluated in HASMCs. The results revealed that chrysin significantly inhibited basal as well as PDGF-induced HASMC proliferation, most likely through the suppression of ERK1/2 phosphorylation. However, chrysin did not significantly reduce PDGF-induced apoptosis of HASMCs. The present study indicated that chrysin may be a promising medication for controlling airway remodeling and clinical manifestations of asthma.
\end{abstract}

\section{Introduction}

Asthma is a complex chronic airway inflammatory disease, which is characterized by reversible airflow obstruction, bronchial hyperresponsiveness, airway inflammation and airway

Correspondence to: Dr Gan-Zhu Feng or Dr Qiang Du, Department of Respiratory Medicine, The Second Affiliated Hospital of Nanjing Medical University, 121 Jiangjiayuan Road, Nanjing, Jiangsu 210011, P.R. China

E-mail: fenggz@njmu.edu.cn

E-mail: jingshuyue@163.com

\section{${ }^{*}$ Contributed equally}

Key words: asthma, human airway smooth muscle cells, platelet-derived growth factor, chrysin, proliferation remodeling. Among these, airway remodeling, comprising a range of structural alterations, including increased deposition of extracellular matrix proteins (ECMs), epithelial denudation with goblet cell metaplasia, angiogenesis and increased airway smooth muscle (ASM) mass, has been proposed to result in persistent airflow limitation and a decreased baseline lung function (1-3).

A number of studies have demonstrated that ASM may participate in multiple processes associated with asthma $(4,5)$. ASM cells are considered to be the main cell type involved in bronchial hyperresponsiveness due to their contractibility. The ASM not only serves as the major target of inflammatory mediators in the asthmatic inflammatory process, but also exerts pro-inflammatory and immunomodulatory functions through expressing a host of cell adhesion molecules, responding and secreting a myriad of cytokines and growth factors and upregulating the expression of toll-like receptors in ASM cells (6). Furthermore, increases in the ASM mass have a key role in asthmatic bronchial remodeling, and hyperplasia and hypertrophy of airway smooth muscle cells are considered to be the primary cause of airway obstruction $(1,4,5)$. The mechanisms accounting for ASM hyperplasia include increased proliferation, reduced apoptosis and enhanced migration of myofibroblasts within the ASM layer (4). Proliferation of ASM cells can be induced by a variety of mitogens, including growth factors, cytokines, inflammatory mediators and enzymes, such as platelet-derived growth factor (PDGF), epidermal growth factor (EGF), endothelin-1 and tryptase $(4,7)$. Inhibiting ASM-cell proliferation can be an effective approach for the treatment of asthma. However, ASM remodeling is insensitive to currently used asthma medications, which are usually effective in controlling acute asthma exacerbation and bronchial inflammation (8).

Flavonoids, commonly present in vegetables, nuts, fruits, beverages and herbal remedies, are health-promoting and disease-preventing dietary supplements (9). Chrysin (5,7-dihydroxyflavone) is a natural flavonoid, which is contained in medicinal herbs $(10,11)$. Previous studies showed that chrysin exerts multiple biological activities, including anti-inflammatory, anti-proliferative and anti-oxidative effects (12-14). Chrysin is beneficial for asthma in numerous aspects $(15,16)$; however, the target cells and the mechanisms involved have 
remained to be identified. The proliferation of ASM cells is involved in various aspects of the pathogenesis of asthma $(8,17)$. The present study aimed to investigate whether chrysin affects basal and PDGF-induced proliferation of human ASM cells (HASMCs) as well as the possible underlying mechanisms.

\section{Materials and methods}

Reagents. Dulbecco's modified Eagle's medium (DMEM) and fetal bovine serum (FBS) were purchased from (Thermo Fisher Scientific, Waltham, MA, USA). Chrysin (purity, 97\%) was obtained from Invitrogen-Gibco (Paisley, UK). Recombinant human PDGF-BB was purchased from PeproTech (Rocky Hill, NJ, USA). Cell Counting Kit-8 (CCK-8; cat. no. CK04) and Annexin V-fluorescein isothiocyanate (FITC) Apoptosis Detection kit (cat. no. KGA107) were purchased from Dojindo (Kumamoto, Japan) and KeyGen Biotech (Nanjing, China), respectively. The Total Protein Extraction kit (cat. no. KGP250) was purchased from KeyGen Biotech. Rabbit polyclonal antibody against p44/42 mitogen-activated protein kinase (MAPK) extracellular signal-regulated kinase (ERK)1/2 (cat no. 9102) and rabbit monoclonal antibody against phospho (p)-p44/42 MAPK (ERK1/2) (Thr202/Tyr204; cat no. 4370) were from Cell Signaling Technology, Inc. (Beverly, MA, USA). Mouse monoclonal antibody against GAPDH (cat no. MB001) was purchased from Bioworld Technology (St. Louis Park, MN, USA). Horseradish peroxidase (HRP)-conjugated goat anti-rabbit immunoglobulin (Ig)G (H\&L) (cat no. BS13278) and HRP-conjugated goat anti-mouse $\operatorname{IgG}(\mathrm{H} \& \mathrm{~L})$ (cat no. BS12478) were obtained from Bioworld Technology (St. Louis Park, MN, USA). The Bicinchoninic acid (BCA) Protein Assay kit (cat. no. P0012) and Enhanced Chemiluminescence (ECL) Detection kit (cat. no. P1007-1) were obtained from Beyotime Institute of Biotechnology (Nantong, China) and Jinan Ubio Biological Technology (Jinan, China), respectively.

Cell culture. HASMCs were purchased from Sciencell Research Laboratories (cat. no. 3400; Carlsbad, CA, USA). The cells were grown in DMEM medium containing $10 \%$ FBS, $100 \mathrm{IU} / \mathrm{ml}$ penicillin and $100 \mu \mathrm{g} / \mathrm{ml}$ streptomycin (Invitrogen-Gibco), and incubated at $37^{\circ} \mathrm{C}$ in a humidified $5 \%$ $\mathrm{CO}_{2}$ atmosphere (18). Cells at passage 4-8 were used in all experiments.

Proliferation. HASMCs cultured in DMEM supplemented with penicillin, streptomycin and $10 \%$ FBS were seeded in 96-well plates at a density of 5,000 or 3,500 cells per well for treatments for 24 and $48 \mathrm{~h}$, respectively. The cells were then serum-deprived in DMEM containing 0.5\% FBS for $24 \mathrm{~h}$ when they were $\sim 60-70 \%$ confluent. Cells were treated with chrysin $(10,20$ or $40 \mu \mathrm{M})$ alone or pre-treated with chrysin for $30 \mathrm{~min}$ prior to stimulation with PDGF-BB (10 ng/ml). After 24 or $48 \mathrm{~h}$, the Cell Counting kit- 8 assay was used to assess the number of viable cells. After the medium was aspirated, CCK-8 solution $(10 \mu \mathrm{l})$ diluted in serum-free DMEM $(100 \mu \mathrm{l})$ was added to each well and the cells were further incubated at $37^{\circ} \mathrm{C}$ in the presence of $5 \% \mathrm{CO}_{2}$ for $2 \mathrm{~h}$. The absorbance of the wells was measured at $450 \mathrm{~nm}$ using the Bio-Rad iMark ${ }^{\mathrm{TM}}$ Microplate Reader (Bio-Rad Laboratories, Hercules, CA, USA).
Apoptosis assay. An Annexin V-FITC Apoptosis Detection kit was used to determine the percentage of apoptotic cells. Briefly, cells were seeded in six-well plates, cultured as described above, and growth-arrested in DMEM containing $0.5 \%$ FBS for $24 \mathrm{~h}$ when reaching $\sim 70 \%$ confluence. The cells were then stimulated with PDGF-BB $(10 \mathrm{ng} / \mathrm{ml})$ with or without 30 -min chrysin $(20 \mu \mathrm{M})$ pre-treatment, or chrysin $(20 \mu \mathrm{M})$ alone for $24 \mathrm{~h}$. The treated cells were trypsinzed and washed with phosphate-buffered saline (PBS) twice, and subsequently incubated with Annexin V-FITC and propidium iodide (PI). Quantification of apoptosis and necrosis was performed using flow cytometry (BD FACSCanto ${ }^{\mathrm{TM}} \mathrm{II}$; BD Biosciences, Franklin Lakes, NJ, USA).

Western blot analysis. HASMCs were seeded in six-well plates at a density of $2 \times 10^{5}$ cells/well and cultured as described above and subsequently starved in DMEM containing $0.5 \%$ FBS overnight. The growth-arrested cells were stimulated with PDGF-BB $(10 \mathrm{ng} / \mathrm{ml})$ for $30 \mathrm{~min}$ with or without 30 -min chrysin $(20 \mu \mathrm{M})$ pre-treatment, or chrysin $(20 \mu \mathrm{M})$ alone. After the treatments, cells were immediately washed with ice-cold PBS twice and lysed in lysis buffer containing $5 \mu \mathrm{l}$ phosphatase inhibitors, $1 \mu \mathrm{l}$ protease inhibitors and $5 \mu 1100 \mathrm{mM}$ phenylmethanesulfonylfluoride in $1 \mathrm{ml}$ buffer (Total Protein Extraction kit). The lysates were centrifuged at $14,000 \mathrm{xg}$ for $15 \mathrm{~min}$ at $4^{\circ} \mathrm{C}$ to obtain the total cell extracts. The BCA Protein Assay kit was used to determine the protein concentration. Equal amounts of protein extracts $(20 \mu \mathrm{g})$ were subjected to $10 \%$ SDS-PAGEand transferred onto polyvinylidene difluoride membranes (Millipore, Billerica, MA, USA). Membranes were blocked in a blocking buffer (5\% non-fat milk, $20 \mathrm{mM}$ Tris- $\mathrm{HCl}, 150 \mathrm{mM} \mathrm{NaCl}$ and $0.05 \%$ Tween-20; Biosharp, Hefei, China) at room temperature for $2 \mathrm{~h}$ and then incubated with the primary antibodies, anti-GAPDH $(1: 5,000$ dilution), anti-ERK1/2 (1:1,000 dilution) and anti-p-ERK1/2 (1:1,000 dilution) at $4^{\circ} \mathrm{C}$ overnight. Subsequently, membranes were washed with $20 \mathrm{mM}$ Tris- $\mathrm{HCl}, 150 \mathrm{mM} \mathrm{NaCl}$ and $0.05 \%$ Tween-20 (TBST) three times, for $15 \mathrm{~min}$ each wash. Following this, the membranes were incubated for $1.5 \mathrm{~h}$ with the HRP-conjugated goat anti-rabbit IgG antibodies for ERK1/2 and p-ERK1/2, and the HRP-conjugated goat anti-mouse IgG antibody for GAPDH. The membranes were then washed with TBST 3 times, for $15 \mathrm{~min}$ each wash. Immunoreactive bands were detected using ECL reagents. The intensity of bands was quantified using the Bio-Rad Gel Doc/Chemi Doc Imaging System and Image Lab software, version 4.0 (Bio-Rad Laboratories). GAPDH was used as an internal control for protein loading.

Statistical analysis. Values are expressed as the mean \pm standard error of the mean. Differences between groups were analyzed using the two-tailed Student's t-test with SPSS software, version 19 (IBM SPSS, Armonk, NY, USA). P<0.05 was considered to indicate a statistically significant difference between values.

\section{Results}

Chrysin inhibits PDGF-induced HASMC proliferation. To clarify the mechanism of the beneficial effects of chrysin in 
A

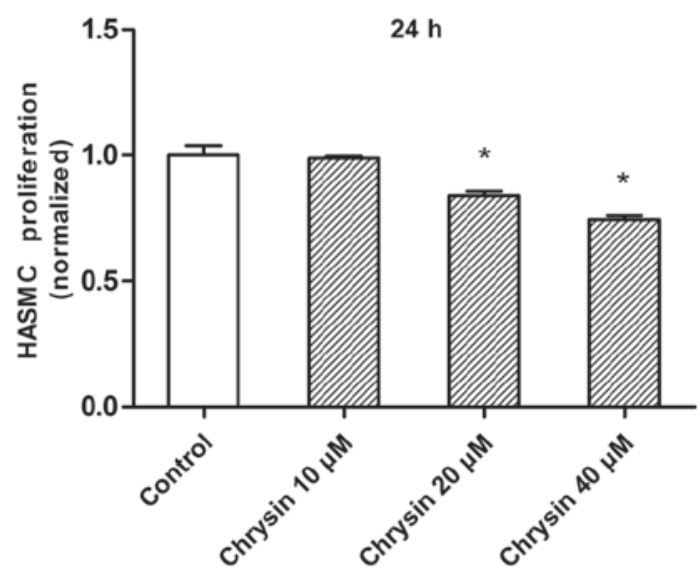

C

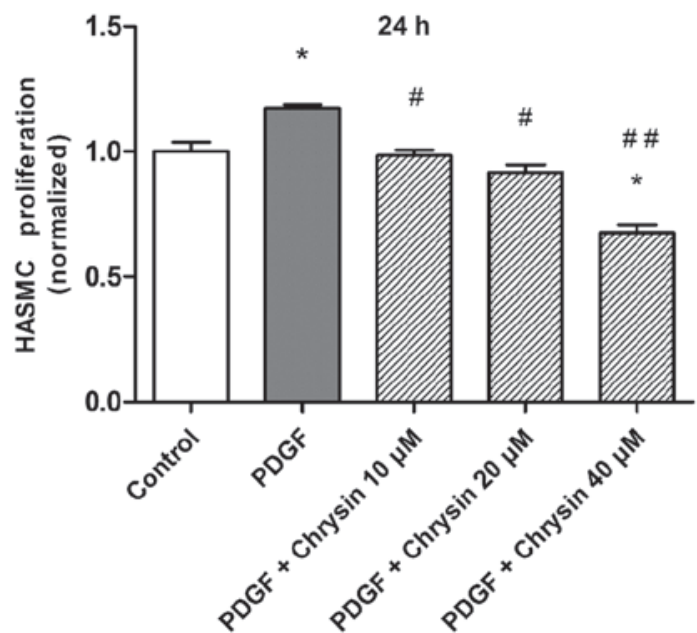

B

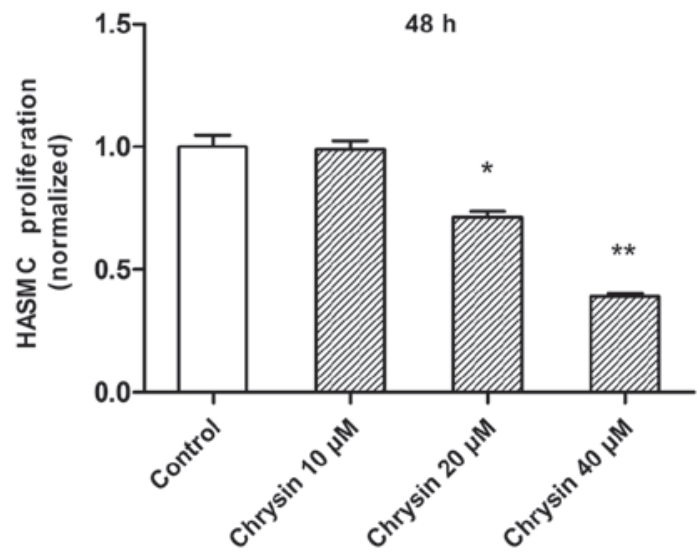

D

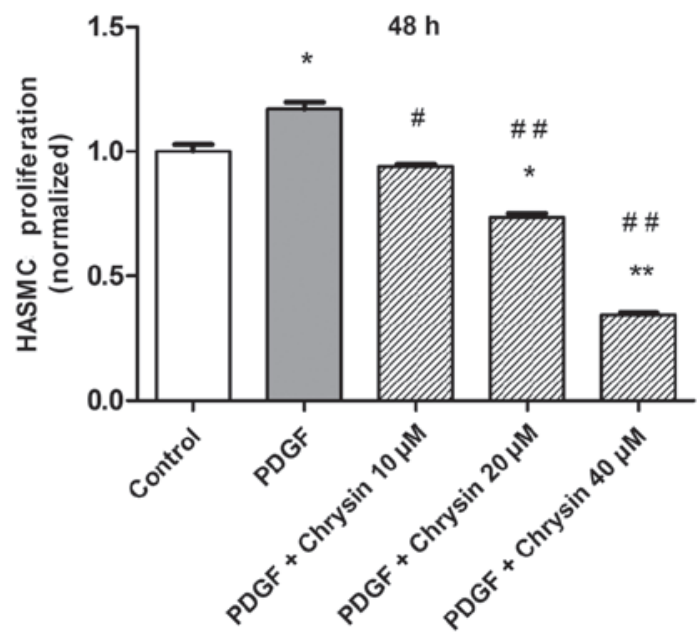

Figure 1. Chrysin inhibits basal as well as PDGF-stimulated proliferation of HASMCs. Growth-arrested cells were treated with (A and B) chrysin (10, 20 or $40 \mu \mathrm{M}$ ) alone or (C and D) pre-treated with chrysin for $30 \mathrm{~min}$ before stimulation with PDGF-BB (10 ng/ml). After 24 or 48 h, A Cell Counting Kit- 8 assay was used to assess cell proliferation. Values are expressed as the mean \pm standard error of the mean from three individual experiments. $\mathrm{P}<0.05$, ${ }^{* *} \mathrm{P}<0.001$ vs. control group; ${ }^{\#} \mathrm{P}<0.05,{ }^{\#} \mathrm{P}<0.001$ vs. PDGF-stimulated treatment group. PDGF, platelet-derived growth factor; HASMC, human airway smooth muscle cell.

patients with asthma, the present study investigated the role of chrysin on the basal as well as PDGF-induced proliferation in HASMCs. Chrysin inhibited the proliferation of HASMCs in a dose- and time-depended manner. Chrysin ( 20 or $40 \mu \mathrm{M}$ for 24 or $48 \mathrm{~h}$ ) significantly suppressed the proliferation of HASMCs (Fig. 1A and B). Subsequently, the present study examined whether chrysin was able to block PDGF-BB-induced HASMC proliferation. The results showed that PDGF-BB enhanced the proliferation, while chrysin significantly abrogated the PDGF-BB induced proliferation of HASMCs, resulting in a decreased number of viable cells compared with that in the control group at high chrysin concentrations (Fig. 1C and D).

Chrysin does not significantly affect the apoptotic rate of $H A S M C s$. In order to investigate whether the anti-proliferative effects of chrysin were attributable to the induction of apoptosis, the present study next examined the effects of chrysin on HASMC apoptosis. An Annexin V-FITC apoptosis assay was used to determine the percentage of apoptotic cells. The results showed that PDGF-BB had no effects on the apoptotic rate compared with that in the control group. Treatment with chrysin increased the apoptotic rate of the HASMCs, but not significantly. However, chrysin had no effect on the apoptotic rate of cells treated with PDGF-BB (Fig. 2).
Chrysin abrogates PDGF-induced ERK1/2 phosphorylation. It has been established that ERK1/2 is activated during PDGF-stimulated cell proliferation (19). Therefore, the present study explored whether chrysin inhibited the proliferation of HASMCs by reducing the phosphorylation of ERK1/2. As shown in Fig. 3, PDGF-BB significantly increased the phosphorylation of ERK1/2 compared with that in the control group, which was significantly abrogated by chrysin. However, chrysin treatment alone did not affect the phoshorylation levels of ERK1/2. In addition, neither PDGF-BB nor chrysin had any effect on total ERK1/2 expression.

\section{Discussion}

The present study investigated the effects of chrysin on HASMCs. The results showed that chrysin inhibited basal and PDGF-induced proliferation and slightly, but not significantly, enhanced apoptosis. This effect was associated with decreased phosphorylation of ERK1/2.

Asthma is a complex chronic airway inflammatory disease, which is accompanied with oxidative stress. Increased production of reactive oxygen species has been identified to cause airway inflammation, bronchial hyperreactivity, increased vascular permeability, tissue injury and airway 

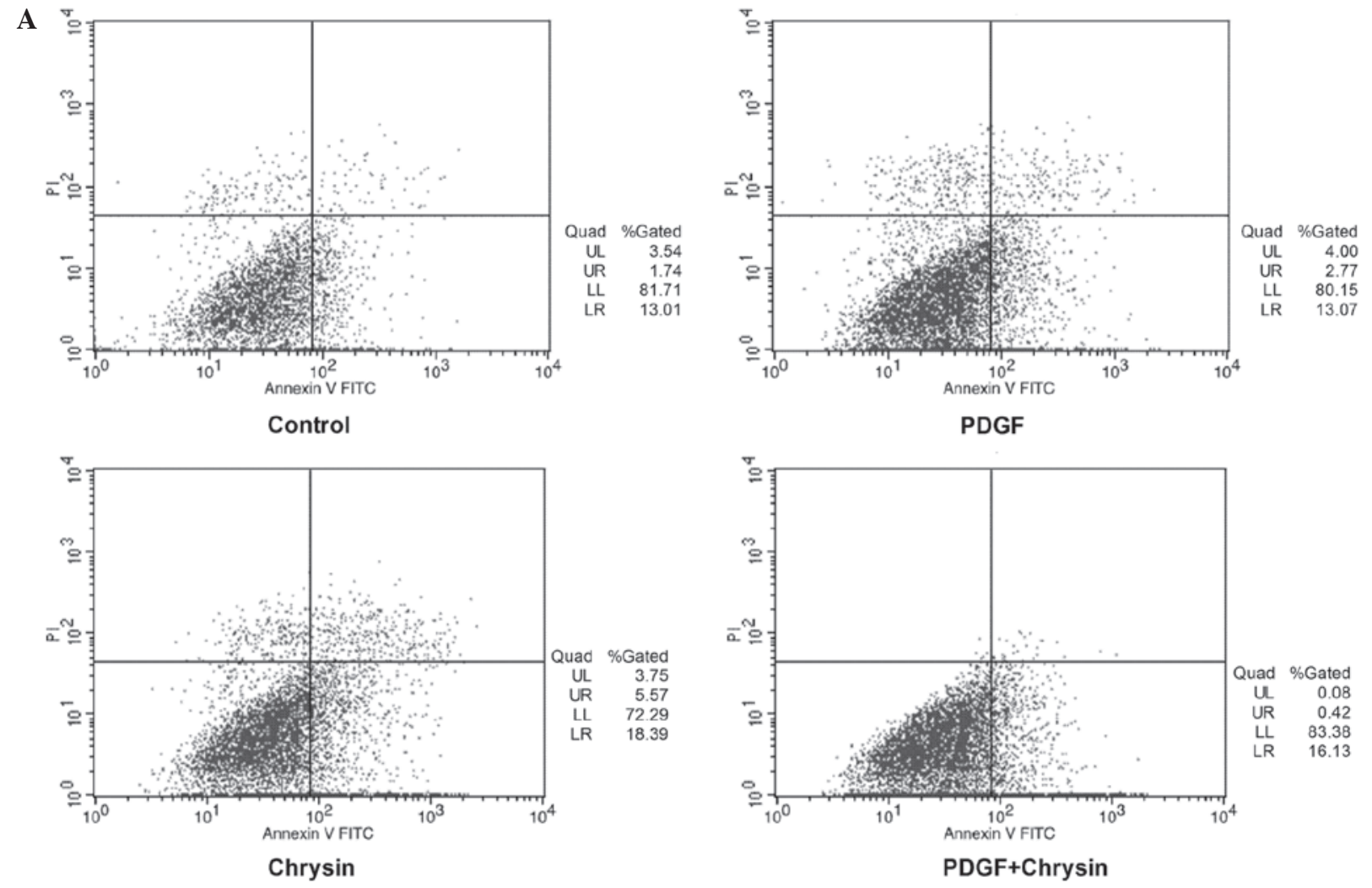

B

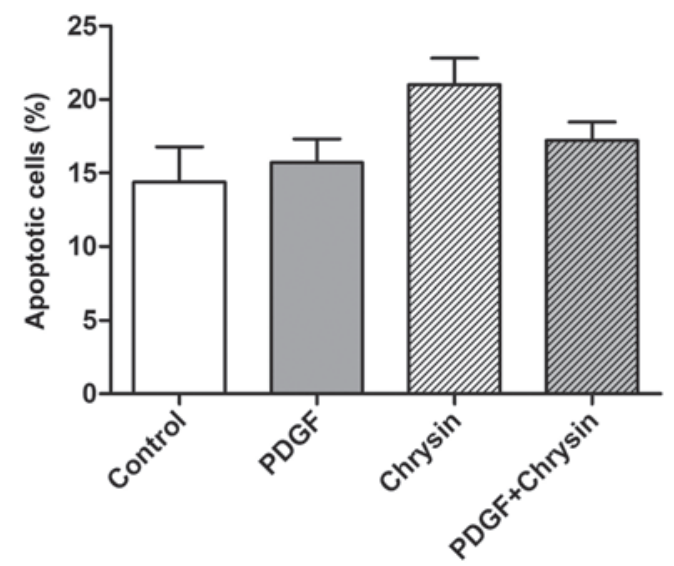

Figure 2. Chrysin does not significantly inhibit apoptosis of human airway smooth muscle cells. (A) Annexin V-FITC apoptosis detection kit was used to determine the percentage of apoptotic cells. Growth-arrested cells were stimulated with PDGF-BB $(10 \mathrm{ng} / \mathrm{ml})$ with or without 30 -min chrysin $(20 \mu \mathrm{M})$ pre-treatment, or chrysin $(20 \mu \mathrm{M})$ alone for $24 \mathrm{~h}$. (B) Bar graph representing the percent of apoptosis cells by densitometric analysis. There is no significant difference between groups. Values are expressed as the mean \pm standard error of the mean from three individual experiments. PDGF, platelet-derived growth factor; FITC, fluorescein isothiocyanate; PI, propidium iodide; UL, upper left; LR, lower right; Quad, quadrant.

remodeling $(1,20,21)$. Previous studies have demonstrated that chrysin has an anti-oxidant function $(12,13)$. Chrysin may therefore be a suitable medication for treating asthma. A previous study reported that chrysin inhibits mast cell-derived allergic inflammatory reactions in vivo and in vitro by blocking histamine release and pro-inflammatory cytokine expression (16). Du et al (15) and Lee et al (22) have demonstrated that chrysin exerts anti-asthmatic effects in animal models. However, the target cells and mechanisms involved in chrysin-modulated amelioration of asthma have remained elusive. Studies have confirmed that chrysin exerts anti-proliferative effects on numerous cancer cell lines, including A549 and PC-3 $(23,24)$, and also significantly suppresses the proliferation of human umbilical vein endothelial cells in a concentration-dependent manner (25). Since ASM have a crucial role in airway remodeling of asthma, primarily due to their increased mass, the present study investigated whether chrysin had an effect on the proliferation of HASMCs. The results revealed that chrysin inhibited HASMCs proliferation in a dose- and time-depended manner. PDGF-BB is a mitogen, which was extensively proved to potently induce the proliferation of ASM cells in vitro as well as in vivo (26-28). Furthermore, it has been reported that chrysin can inhibit PDGF-induced proliferation in rat vascular smooth muscle cell (19). In line with this finding, the results of the present study also indicated that chrysin suppressed the proliferation of HASMCs induced by PDGF-BB. This capacity 
A

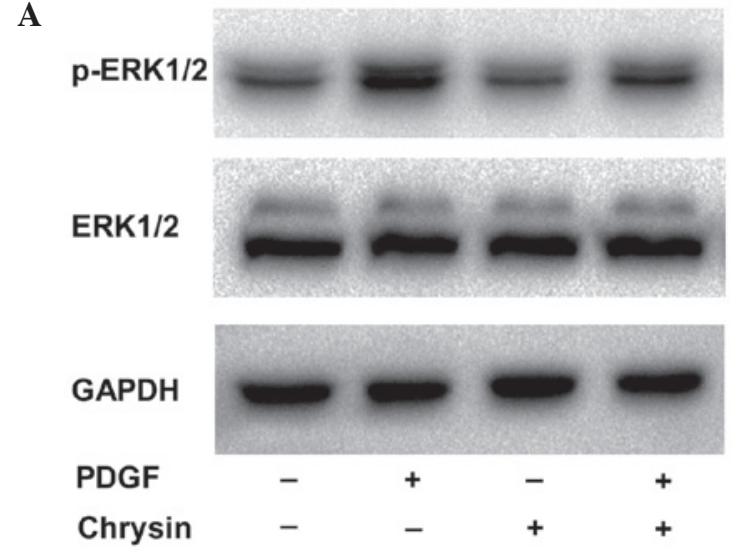

B

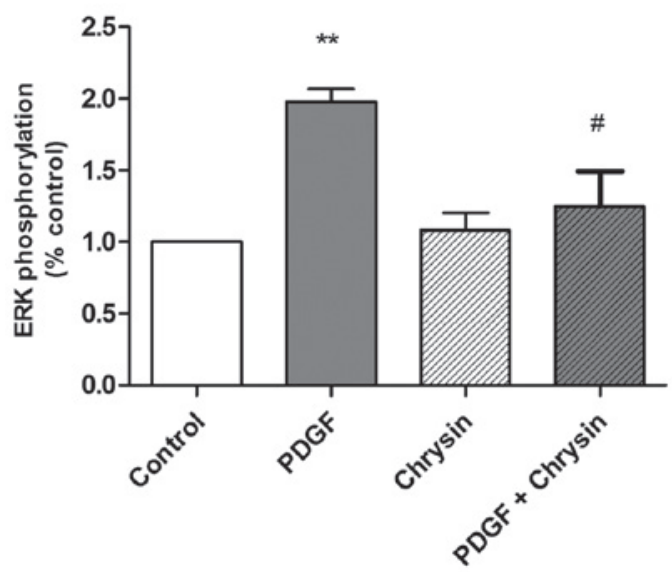

Figure 3. Chrysin inhibits the effect of PDGF-BB on the activation of ERK1/2. (A) HASMCs were stimulated with PDGF-BB $(10 \mathrm{ng} / \mathrm{ml})$ for $30 \mathrm{~min}$ with or without pre-treatment with chrysin $(20 \mu \mathrm{M})$ for $30 \mathrm{~min}$. (B) Bar graph representing the phosphorylation levels obtained by densitometric analysis. Values are expressed as the mean \pm standard error of the mean from three individual experiments. ${ }^{* *} \mathrm{P}<0.001$ vs. control group; ${ }^{\#} \mathrm{P}<0.05$ vs. PDGF-stimulated treatment group. PDGF, platelet-derived growth factor; HASMC, human airway smooth muscle cell; p-ERK, phosphorylated extracellular signal-regulated kinase.

may be of potential clinical value in the treatment of airway remodeling.

The increased ASM mass in patients with asthma is associated with reduced apoptosis (4). Apoptosis has been observed to be responsible for the growth inhibition by chrysin in A549 and HepG2 cells $(23,29)$. The present study explored whether chrysin inhibited the growth of ASM through inducing apoptosis. The results showed that chrysin induced apoptosis of HASMCs, although without statistical significance. This finding implied that the anti-proliferative effects of chrysin were not primarily the promotion of apoptosis.

ERK is required for HASMC proliferation and the phosphorylation of ERK1/2 is enhanced during PDGF-induced ASM-cell proliferation (30-32). Furthermore, chrysin has been confirmed to restore PDGF-induced ERK1/2 phosphorylation in rat vascular smooth muscle cell (19). To further elucidate the molecular mechanisms involved in the anti-proliferative effects of chrysin, the present study assessed whether chrysin inhibited the proliferation of HASMCs through the ERK pathway. The results revealed that chrysin reduced PDGF-induced ERK1/2 phosphorylation in HASMCs, indicating that chrysin may inhibit PDGF-induced proliferation through the ERK signaling pathway. However, chrysin alone had no effect on the basal phosphorylation of ERK1/2 and total ERK1/2. This finding indicated that other pathways contribute to the anti-proliferative effects of chrysin. Phosphoinositol-3-kinase (P13K), p38-MAPK, c-Jun N-terminal kinase, phospholipase C, protein kinase $\mathrm{C}$, tyrosine kinases and CCAAT/enhancer binding protein-a are also involved in ASM-cell proliferation $(7,33)$. Chrysin has been proved to induce growth inhibition and reduce the phosphorylation of Akt in A549 cells (23). Decreased proliferation induced by chrysin was observed in human and murine melanoma cells, which is associated with the activation of p38-MAPK (34). Therefore, the abovementioned signaling molecules may be additional targets of chrysin in ASM cells.

The PDGF - PDGF receptor (PDGFR) axis is involved in ASM-cell proliferation $(35,36)$. It has remained elusive whether chrysin affects the interaction between PDGF and PDGFR or the downstream signaling of this axis to inhibit proliferation. A complex signaling network consisting of numerous signaling molecules participates in the proliferative process (33). Hence, it is possible that chrysin has a role in other pathways. In addition, asthma remodeling is associated with ASM migration (4). Previous studies suggested that chrysin inhibited the migration of cancer cells, endothelial cells and even vascular smooth muscle cells $(19,37,38)$, indicating that chrysin may also affect ASM-cell migration. Since numerous other cell types, including inflammatory cells, participate in the pathology of asthma, ASM may not be the sole target cell type of chrysin in ameliorating asthma. Therefore, additional studies are required to gain deeper insight into the mechanisms of action of chrysin and provide data supporting its clinical application.

In conclusion, the present study demonstrated that chrysin inhibited PDGF-induced proliferation of HASMCs through reducing the phosphorylation of ERK1/2, suggesting that chrysin mat be a promising medication for controlling airway remodeling and clinical manifestations of asthma.

\section{Acknowledgements}

This study was supported by the Natural Science Foundation of Jiangsu Province (no. BK20131436).

\section{References}

1. Al-Muhsen S, Johnson JR and Hamid Q: Remodeling in asthma. J Allergy Clin Immunol 128: 451-462, 2011.

2. Bergeron C and Boulet LP: Structural changes in airway diseases: Characteristics, mechanisms, consequences and pharmacologic modulation. Chest 129: 1068-1087, 2006.

3. Manuyakorn W, Howarth PH and Holgate ST: Airway remodelling in asthma and novel therapy. Asian Pac J Allergy Immunol 31: 3-10, 2013.

4. Ozier A, Allard B, Bara I, Girodet PO, Trian T, Marthan R and Berger P: The pivotal role of airway smooth muscle in asthma pathophysiology. J Allergy (Cairo) 2011: 742710, 2011.

5. Bara I, Ozier A, Tunon de Lara JM, Marthan R and Berger P: Pathophysiology of bronchial smooth muscle remodelling in asthma. Eur Respir J 36: 1174-1184, 2010.

6. Damera G, Tliba O and Panettieri RA Jr: Airway smooth muscle as an immunomodulatory cell. Pulm Pharmacol Ther 22: 353-359, 2009.

7. Stewart AG: Airway wall remodelling and hyperresponsiveness: Modelling remodelling in vitro and in vivo. Pulm Pharmacol Ther 14: 255-265, 2001. 
8. Girodet PO, Ozier A, Bara I, Tunon de Lara JM, Marthan R and Berger P: Airway remodeling in asthma: New mechanisms and potential for pharmacological intervention. Pharmacol Ther 130: 325-337, 2011

9. Moon YJ, Wang X and Morris ME: Dietary flavonoids: Effects on xenobiotic and carcinogen metabolism. Toxicol In Vitro 20: $187-210,2006$

10. Williams CA, Harborne JB, Newman M, Greenham J and Eagles J: Chrysin and other leaf exudate flavonoids in the genus pelargonium. Phytochemistry 46: 1349-1353, 1997.

11. Rapta P, Misik V, Stasko A and Vrabel I: Redox intermediates of flavonoids and caffeic acid esters from propolis: An EPR spectroscopy and cyclic voltammetry study. Free Radic Biol Med 18: 901-908, 1995

12. Cho H, Yun CW, Park WK, Kong JY, Kim KS, Park Y, Lee S and Kim BK: Modulation of the activity of pro-inflammatory enzymes, COX-2 and iNOS, by chrysin derivatives. Pharmacol Res 49: 37-43, 2004

13. Lapidot T, Walker MD and Kanner J: Antioxidant and prooxidant effects of phenolics on pancreatic beta-cells in vitro. J Agric Food Chem 50: 7220-7225, 2002.

14. Phan T, Yu XM, Kunnimalaiyaan M and Chen H: Antiproliferative effect of chrysin on anaplastic thyroid cancer. J Surg Res 170: $84-88,2011$.

15. Du Q, Gu X, Cai J, Huang M and Su M: Chrysin attenuates allergic airway inflammation by modulating the transcription factors T-bet and GATA-3 in mice. Mol Med Rep 6: 100-104, 2012.

16. Bae Y,Lee S and Kim SH: Chrysin suppresses mast cell-mediated allergic inflammation: Involvement of calcium, caspase-1 and nuclear factor- $\kappa$ B. Toxicol Appl Pharmacol 254: 56-64, 2011

17. Lommatzsch M: Airway hyperresponsiveness: New insights into the pathogenesis. Semin Respir Crit Care Med 33: 579-587, 2012

18. Zha WJ, Qian Y, Shen Y, Du Q, Chen FF, Wu ZZ, Li X and Huang M: Galangin abrogates ovalbumin-induced airway inflammation via negative regulation of NF- $\kappa$ B. Evidence-Based Complement Alternat Med 2013: 767689, 2013.

19. Lo HM, Wu MW, Pan SL, Peng CY, Wu PH and Wu WB Chrysin restores PDGF-induced inhibition on protein tyrosine phosphatase and reduces PDGF signaling in cultured VSMCs. J Nutr Biochem 23: 667-678, 2012.

20. Kirkham P and Rahman I: Oxidative stress in asthma and COPD Antioxidants as a therapeutic strategy. Pharmacol Ther 111: 476-494, 2006

21. Sugiura $H$ and Ichinose $M$ : Oxidative and nitrative stress in bronchial asthma. Antioxid Redox Signal 10: 785-797, 2008.

22. Lee JY, Kim JM and Kim CJ: Flavones derived from nature attenuate the immediate and late-phase asthmatic responses to aerosolized-ovalbumin exposure in conscious guinea pigs. Inflamm Res 63: 53-60, 2014.

23. Shao JJ, Zhang AP, Qin W, Zheng L, Zhu YF and Chen X: AMP-activated protein kinase (AMPK) activation is involved in chrysin-induced growth inhibition and apoptosis in cultured A549 lung cancer cells. Biochem Biophys Res Commun 423: 448-453, 2012

24. Samarghandian S, Afshari JT and Davoodi S: Chrysin reduces proliferation and induces apoptosis in the human prostate cancer cell line Pc-3. Clinics (Sao Paulo) 66: 1073-1079, 2011.
25. Ahn MR, Kunimasa K, Kumazawa S, Nakayama T, Kaji K, Uto Y, Hori H, Nagasawa H and Ohta T: Correlation between antiangiogenic activity and antioxidant activity of various components from propolis. Mol Nutr Food Res 53: 643-651, 2009.

26. Barnes PJ: Immunology of asthma and chronic obstructive pulmonary disease. Nat Rev Immunol 8: 183-192, 2008.

27. Hirota JA, Ask K, Farkas L, Smith JA, Ellis R, Rodriguez-Lecompte JC, Kolb M and Inman MD: In vivo role of platelet-derived growth factor-BB in airway smooth muscle proliferation in mouse lung. Am J Respir Cell Mol Biol 45: 566-572, 2011.

28. Hirst SJ, Barnes PJ and Twort CH: PDGF isoform-induced proliferation and receptor expression in human cultured airway smooth muscle cells. Am J Physiol 270: L415-L428, 1996.

29. Deng X, Zhao X, Lan Z, Jiang J, Yin W and Chen L: Anti-tumor effects of flavonoids from the ethnic medicine docynia delavayi (Franch.) Schneid. And its possible mechanism. J Med Food 17: 787-794, 2014

30. Yu ZH, Wang YX, Song Y, Lu HZ, Hou LN, Cui YY and Chen HZ: Up-regulation of $\mathrm{KCa} 3.1$ promotes human airway smooth muscle cell phenotypic modulation. Pharmacol Res 77: 30-38, 2013.

31. Movassagh H, Shan L, Halayko AJ, Roth M, Tamm M, Chakir J and Gounni AS: Neuronal chemorepellent Semaphorin 3E inhibits human airway smooth muscle cell proliferation and migration. J Allergy Clin Immunol 133: 560-567, 2014

32. Lee JH, Johnson PR, Roth M, Hunt NH and Black JL: ERK activation and mitogenesis in human airway smooth muscle cells. Am J Physiol Lung Cell Mol Physiol 280: L1019-L1029, 2001.

33. Pelaia G, Renda T, Gallelli L, Vatrella A, Busceti MT, Agati S, Caputi M, Cazzola M, Maselli R and Marsico SA: Molecular mechanisms underlying airway smooth muscle contraction and proliferation: Implications for asthma. Respir Med 102: 1173-1181, 2008

34. Pichichero E, Cicconi R, Mattei Mand Canini A: Chrysin-induced apoptosis is mediated through $\mathrm{p} 38$ and Bax activation in B16-F1 and A375 melanoma cells. Int J Oncol 38: 473-483, 2011.

35. Tallquist $\mathrm{M}$ and Kazlauskas A: PDGF signaling in cells and mice. Cytokine Growth Factor Rev 15: 205-213, 2004.

36. Gosens R, Stelmack GL, Dueck G, McNeill KD, Yamasaki A Gerthoffer WT, Unruh H, Gounni AS, Zaagsma J and Halayko AJ: Role of caveolin-1 in p42/p44 MAP kinase activation and proliferation of human airway smooth muscle. Am J Physiol Lung Cell Mol Physiol 291: L523-L534, 2006.

37. Yang B, Huang J, Xiang T, Yin X, Luo X, Huang J, Luo F, $\mathrm{Li} \mathrm{H}, \mathrm{Li} \mathrm{H}$ and Ren G: Chrysin inhibits metastatic potential of human triple-negative breast cancer cells by modulating matrix metalloproteinase-10, epithelial to mesenchymal transition and PI3K/Akt signaling pathway. J Appl Toxicol 34: 105-112, 2014

38. Lin CM, Shyu KG, Wang BW, Chang H, Chen YH and Chiu JH: Chrysin suppresses IL-6-induced angiogenesis via down-regulation of JAK1/STAT3 and VEGF: An in vitro and in ovo approach. J Agric Food Chem 58: 7082-7087, 2010. 